This is the author's final, peer-reviewed manuscript as accepted for publication. The publisher-formatted version may be available through the publisher's web site or your institution's library.

\title{
Financial dependence and growth: diminishing returns to improvement in financial development
}

Leilei Shen

\section{How to cite this manuscript}

If you make reference to this version of the manuscript, use the following information:

Shen, L. (2013). Financial dependence and growth: Diminishing returns to improvement in financial development. Retrieved from http://krex.ksu.edu

\section{Published Version Information}

Citation: Shen, L. (2013). Financial dependence and growth: Diminishing returns to improvement in financial development. Economics Letters, 120(2), 215-219.

Copyright: @ 2013 Elsevier B.V.

Digital Object Identifier (DOI): doi:10.1016/j.econlet.2013.04.018

Publisher's Link: http://www.sciencedirect.com/science/article/pii/S0165176513001894

This item was retrieved from the K-State Research Exchange (K-REx), the institutional repository of Kansas State University. K-REx is available at http://krex.ksu.edu 


\title{
Financial Dependence and Growth: Diminishing Returns to Improvement in Financial Development
}

\author{
Leilei Shen * \\ Kansas State University
}

April 7, 2013

\begin{abstract}
This paper examines how much financial development facilitates economic growth by nonparametrically estimating the effect of financial development on reducing the costs of external finance to firms. The data reveal substantial evidence of diminishing returns to improvement in financial development.
\end{abstract}

Keywords: Financial Dependence, Growth, Semiparametric Estimation.

JEL Classifications: F3, O4.

${ }^{*}$ Leilei Shen, Department of Economics, 214 Waters Hall, Kansas State University, Manhattan, KS,66506, USA. Phone: (785) 532-4580. Fax: (785) 532-6919. Email: lshen@k-state.edu 


\section{Introduction}

There has been a growing literature on financial institutions and growth. Dating as far back as Schumpeter (1911), development of a country's financial institutions has a positive influence on the rate of growth of its per capita income. In addition, Rajan and Zingales (1998) show that this effect is more pronounced in the financially dependent industries.

The basic specification in this paper is a semiparametric growth rate function where the interaction between external financial dependence of an industry and financial development of a country enters nonparametrically and the remaining variables are parametric. This paper provides evidence that the effect of financial development and external dependence on finance is non-linear and increasing at a decreasing rate. In other words, parametric estimation of this interaction effect significantly overestimates the interaction when it is small and underestimates it when it is large. In addition, for an improvement in financial development, the parametric estimation assumes the return to financial improvement only varies with industry, whereas the semiparametric specification is able to capture diminishing returns to financial improvement in addition to industry variance. A theoretical paper by Ju and Wei (2011) has formalized how financial improvement only affect financially underdeveloped countries in trade. This paper also shows that welfare effects of positive shocks to the economy are substantially different if one estimates this financial development and external finance dependence effect nonparametrically rather than parametrically. Finally, this paper considers the possibility that measures of financial development for a country are endogenous. Countries that have higher growth rates are more likely to have better financial institutions in place. One might therefore expect the measures of financial development to be positively correlated with the residual in an equation where the dependent variable is growth rates or value added. In the concluding section this paper conducts a simple test of the endogeneity hypothesis.

The rest of this paper is organized as follows: Section 2 describes the model and provides additional details about the data. Section 3 reports the results from single-equation differencing techniques (Yatchew (1997), Yatchew (1998), and Yatchew (1999)) to analyze the effect of external financial dependence and financial development on growth rates. Section 4 utilizes the panel data and reports semiparametric results using time changing measurements of financial development and external finance, and Section 5 concludes. 


\section{Model and Data}

This paper uses the dataset provided by Rajan and Zingales (1998). Growth in value added for an industry is defined as the change in the log of real value added in that industry between 1980 and 1990. External financial dependence of an industry is measured as the median firm's capital expenditures minus cash flow from operations divided by capital expenditures in that industry. There are several measures available for financial development of a country. The first measure this paper uses is fairly traditionalthe ratio of domestic credit plus stock market capitalization to GDP. The second proxy for financial development used in this paper is the accounting standards in a country. A higher score in the accounting standards indicates more disclosure.

The main empirical objective of this paper is to estimate the effect of external financial dependence on financial development on the growth rates. A priori, the relationship between growth rates and external financial dependence interacted with financial development maybe flat, increasing, decreasing or U-shaped; it may be concave or it may have multiple inflection points. I propose therefore to estimate the effect using a semiparametric model.

In addition to an industry's external financial dependence and a country's financial development, a number of variables may influence growth rates and therefore need to be incorporated into the model. These covariates include the conventional arguments of growth rate function - an industry's share of manufacturing in a country, country indicators and industry indicators.

The basic econometric specification is given by:

$$
\begin{aligned}
\text { Growth }_{j k}= & f\left(\text { ExtFinDep }_{j} * \text { FinDev }_{k}\right) \\
& +\beta_{1} \text { ShareofManufacturing } \text { Sh }_{k}+\beta_{2} \text { Controls } \\
& +\beta_{3} \text { CountryIndicators }+\beta_{4} \text { IndustryIndicators }+ \text { constant }+\epsilon_{j k} .
\end{aligned}
$$

I assume little about the function beyond smoothness, thus equation (1) is a growth rate function of partial linear structure $y_{j k}=f\left(x_{j k}\right)+z_{j k} \beta+v$, where the nonparametric component is the interaction between external financial dependence and financial development, and the vector $z$ contains the parametric components, such as industry share and other control variables. The return to improvement in financial development for a country depends on the slope of the function 
$f$ and an industry's external finance dependence: $\partial$ Growt $_{j k} / \partial$ FinDev $_{k}=f^{\prime} * \operatorname{ExtFinDep}_{j}$.

Because the parametric and nonparametric portions of the model are additively separable, the simple differencing techniques can be applied to the partial linear structure easily. The essential idea is to reorder the data so that the values of the nonparametric variable are close to each other, then to take first- or higher-order differences to remove the nonparametric effect and run ordinary least squares regressions of the differenced dependent variable on the differenced parametric explanatory variables. This differencing technique is explained in details in Yatchew (2000), Yatchew (1999) and Yatchew (1997).

\section{Emprical Results}

For comparison purposes I provide estimates of the parametric analogues of equation (1) in column (1) to (5) in Table $1 .{ }^{1}$ I start with total capitalization (private credit plus stock market capitalization) to GDP ratio as the proxy for financial development. Since I use U.S. data to identify the external dependence in column (1)-(3), I drop U.S. data. Column (1) reports the OLS estimates without country and industry fixed effects. Column (2) controls for country and industry fixed effects. Column (3) uses U.S. industry capital growth as a measure of good investment prospects as suggested by Ciccone and Papaioannou (2006). ${ }^{2}$ Column (4) uses the 2SLS method proposed by Ciccone and Papaioannou (2010) to correct for the bias resulting from using the U.S. capital growth as a measure for industry characteristics. ${ }^{3}$ Column (5) uses the same method with additional controls. ${ }^{4}$ Coefficients reported in column (1) through (5) are consistent with those reported in the literature.

Differencing estimates of the parametric component of equation (1) are presented in the last three columns of Table 1 with additional interaction controls (throughout the paper I use thirdorder differencing. Results for other orders of differencing were similar.) Column (6) reports

\footnotetext{
${ }^{1}$ Growth $_{j k}=\gamma$ ExtFinDep $_{j} *$ FinDev $_{k}+\beta_{1}$ Shareof Manufacturing $_{j k}+\beta_{2}$ Controls $+\beta_{3}$ CountryIndicators + $\beta_{4}$ IndustryIndicators + constant $+\epsilon_{j k}$.

${ }^{2}$ I get similar results using U.S. industry sales growth as suggested by Fisman and Love (2007).

${ }^{3}$ As in Ciccone and Papaioannou (2010), to construct global industry investment opportunities, I first estimate Growth $_{j k}=\alpha_{j}+\alpha_{k}+\gamma_{j}$ FinDev $_{k}+\epsilon_{j k}$ and obtain $\widehat{K}_{j}=\widehat{\alpha}_{j}+\widehat{\gamma}_{j}$ FinDev $v_{U S}$. I then use FinDev $* \widehat{K}_{j}$ to instrument for FinDev $* K_{U S}$.

${ }^{4}$ I control for additional interaction terms: Entry Regulation x Industry Turnover as in Fisman and Sarria-Allende (2010), Capital Endowment x Industry Capital Intensity as in Romalis (2004), Entry Regulation x Employment Growth as in Ciccone and Papaioannou (2007), Rule of Law x Industry Complexity as in Nunn (2007), and Labor Market Regulation x Industry Volatility as in Melitz and Cunat (2012).
} 
the differencing estimates of equation (1) by sorting the data based on the interaction between financial development and U.S. external finance dependence. Column (7) reports the estimates from reordering the data based on the interaction between financial development and U.S. capital growth. Column (8) reports the estimates from reordering the data based on the instrumented interaction proposed in Ciccone and Papaioannou (2010). ${ }^{5}$ The estimated industry share effect is negative and significant and do not differ substantially between parametric and semiparametric specifications. The $R^{2}$ is higher in the semiparametric specifications relative to the pure parametric ones.

Returning to the semiparametric specification, I remove the estimated parametric effect from the dependent variable and analyze the nonparametric effect. Figure $1^{6}$ displays the ordered pairs $\left(y_{j k}-z_{j k} \widehat{\beta}, x_{j k}\right)$ as well as kernel estimates of $f$. Parametric null hypotheses may be tested against nonparametric alternatives using the static:

$$
(m N)^{1 / 2} \frac{s_{r e s}^{2}-s_{v}^{2}}{s_{v}^{2}} \rightarrow N(0,1)
$$

under $H_{0}$, where $s_{\text {res }}^{2}$ is the estimate of the residual variance from the parametric regression and $s_{v}^{2}$ is that of the semiparametric regression. When I insert a constant function for $f$ equation (2) constitutes a test of significance of the scale variable against a nonparametric alternative. The resulting test statistic is 10.89 indicating a strong scale effect of external finance dependence and financial development on growth. Next I test a quadratic model for the interaction term. The resulting statistics is 5.80, suggesting that the quadratic model is still inadequate. ${ }^{7}$

\footnotetext{
${ }^{5}$ The parametric analogue of this is column (5) in Table 1.

${ }^{6}$ For the top figure in each panel, y-axis is the average annual compounded growth rate in real value added for the period 1980-1990 for each ISIC industry in each country after differencing with order $\mathrm{m}=3$. For the bottom figure in each panel, $\mathrm{y}$-axis is the slope of function $f$ calculated from kernel approximation with bandwidth $0.35,0.02$, and 0.01 for Panel A, B, and C, respectively. Panel A displays the nonparametric effect of the interaction between financial development (measured as the total capitalization to GDP ratio) and external finance dependence (measured as the fraction of capital expenditures not financed with internal funds by firms in the same industry during the 1980s) under Table 1 column (6) specification. Panel B displays the nonparametric effect of the interaction between financial development and U.S. capital growth under Table 1 column (7) specification. Panel C displays the nonparametric effect under Table 1 column (8) specification. The solid line is a kernel approximation of the nonlinear interaction effect with bandwidth 0.35. The dotted line is the linear approximation of the interaction effect. The industry measure is set to 0 if it is negative for ease of interpretation. The above picture becomes $\mathrm{V}$-shaped if negative values of industry measures are allowed, with the bottom part of $\mathrm{V}$ pointing around 0 , and the linear fitted line does not change. A V-shaped curve still implies diminishing returns to improvement in financial development. The results are robust to other measures of financial development as well.

${ }^{7}$ The nonparametric effect of the interaction term cannot be approximated by a parametric quadratic term. By including the interaction ${ }^{2}$ in column (1)-(5) does not increase $R^{2}$ nor does it change the estimates in Table 1 significantly. In addition, results are robust to other measures of financial development, such as private credit to
} 
For robustness I repeated my estimation and inference procedures using various orders of differencing. Parameter estimates changed little and tests of significance and specification were consistent with the conclusions above.

It is possible that measures of financial development for a country are endogenous. Countries that have higher growth rates are more likely to have better financial institutions in place. One might therefore expect the measures of financial development to be positively correlated with the residual in an equation where the dependent variable is growth rates or value added. This in turn would lead to underestimation of the effect of external financial dependence and financial development. Porta et al. (1998) suggests that the origin of a country's legal system has an effect on the development of a domestic capital market and on the nature of the accounting system. Countries colonized by the British tend to have sophisticated accounting system while countries colonized by the French tend to have poor standards. This suggests using colonial origin of a country's legal system as one instrument. The second instrument I use is rule of law, an index of efficiency and integrity of legal system produced by Business International Corporation, a country-risk rating agency. I modify the specification in equation (1) to allow for a simple form of endogeneity as follows:

$$
y=f(\text { ExtFinDep } * \text { FinDev })+\eta \gamma+z \beta+v
$$

where $\eta$ is defined by the instrumental variable equation FinDev $=$ Instrument $* \pi+\eta$ and $E(v \mid E x t F i n D e p * F i n D e v, \eta, z)=0$ (See Blundell and Duncan (1998) and Newey, Powell, and Vella (1999)). After estimating $\eta$ from an OLS regression, equation (6) is estimated using differencing. The coefficient of $\eta$ is 0.0893 with a standard error of 0.1151 , which would not result in the rejection of the null hypothesis that financial development is exogenous. Using instrumental variable in the pure parametric estimation resulted little change in the coefficient for the interaction between the external finance dependence and financial development and the Hausman (1978) test statistic $\left(\chi_{1}^{2}=0.66\right)$ was also insignificant.

It may be useful to compare this paper's findings to those of other studies. Rajan and Zingales (1998) used the same data averaged over ten year period. Looking at the industry at the 75th GDP ratio, accounting standards, and accounting standards in 1983. Available upon request. 
percentile of external finance dependence, Machinery (0.445), and the 25th percentile, Beverages (0.077), and the country at the 75th percentile of financial dependence, Italy, and the 25th percentile, Philippines, Rajan and Zingales (1998, p. 574) state that "Machinery should grow 1.3 percent faster than Beverages annually, in real terms, in Italy as compared to the Philippines." Using the semiparametric approach, this paper finds that Machinery should grow 37.9 percent faster than Beverages annually in Italy as compared to the Philippines. The difference between the two numbers is significant. The parametric estimation significantly overestimates the interaction between financial development and external finance for financially underdeveloped countries in sectors with a low reliance on external finance and underestimates it for financially developed countries in sectors with a high reliance on external finance. From Rajan and Zingales (1998), for an one percent improvement in financial development, using total capitalization measure for example, leads to a constant return of $0.07 *$ ExternalFinanceDependence percent increase in growth rate for all countries. On the other hand, under the semiparametric specification, an one percent improvement in financial development leads to $0.68 * 0.077$ percent increase in growth rate for Philippines and $0.79 * 0.077$ percent increase in growth rate for Italy in Beverages. In Machinery, it is $1.0 * 0.445$ percent for Philippines and $0.82 * 0.445$ percent for Italy. For an one percent improvement in financial development, Philippines has more to gain than Italy in Machinery due to diminishing returns to improvement in financial development.

\section{Panel Data Analysis}

\subsection{Panel Data Setup}

The availability of several years of data permits me to assess the stability of parametric effects over time as well as the stability of nonparametric scale effect. The testing of these hypotheses will be the two main objectives of the panel data analysis. The basic model is given by $y_{j k t}=$ $f_{t}\left(x_{j k t}\right)+z_{j k t} \beta_{t}+v_{j k t}$. Now the residual is:

$$
v_{j k t}=u_{j k}+\varepsilon_{j k t}
$$


where, conditional on $x$ 's, $E\left(u_{j k}\right)=0, \operatorname{Var}\left(u_{j k}\right)=\sigma_{u}^{2}, E\left(\varepsilon_{j k t}\right)=0, \operatorname{Var}\left(\varepsilon_{j k t}\right)=\sigma_{\varepsilon}^{2}, \operatorname{Cov}\left(\varepsilon_{j k t}, \varepsilon_{j k s}\right)=$ 0 for all $t$.

The presence of country-industry specific effects requires keeping track of how data have been reordered. Data are ordered so that the $x$ 's are in increasing order in period 1. Data in all subsequent periods are initially in the same order as the data in the first period. This only ensures that the corresponding country-specific effects are in the same position in each year, but it's not longer the case that the corresponding $x$ 's are close. Permutation matrices are used to reorder data and quadratic forms to estimate variances, see details in Yatchew (2000). The permutation matrix reorders the data stacked across all periods so that corresponding $x$ 's are close within each period. The OLS estimator applied to the stacked, reordered and differenced data is identical to the estimator applied year by year. However, its asymptotic covariance matrix must account for correlations between residuals over time arising out of the individual specific effect. This requires consistent estimation of $\sigma_{u}^{2}$ and $\sigma_{\varepsilon}^{2}$. Estimates of $\sigma_{u}^{2}$ and $\sigma_{\varepsilon}^{2}$ will be used to test the stability of the nonparametric effect.

\subsection{Empirical Results}

The estimation of the nonparametric component using the pooled data where the estimated parametric effects have been removed using total capitalization to GDP ratio as the measurement of financial development looks similar to Figure $1 .^{8}$ After getting an estimate of $\beta$ from the stacked, reordered and differenced data, I obtain $s_{v}^{2}=0.21, s_{u}^{2}=0.18$ and by subtraction $s_{\varepsilon}^{2}=0.11$. Thus, about $86 \%$ of the variance of the residual is attributable to the country-industry specific effect. To test constancy of parametric effects over time, the estimated covariance matrix is used in the conventional asymptotic chi-square statistics for testing linear restrictions. The test statistic is 14.76 , indicating rejection. Casual comparison of year by year estimation would suggest that they are not too different. However, since the residuals are dominated by a country-specific effect and the explanatory variables are highly correlated over time, coefficient estimates are also highly correlated over time. Therefore, even small differences are statistically significant. I also test the equality of nonparametric regression functions. The standardized statistic has a standard normal distribution under the null hypothesis. The test statistic is 0.48 , indicating that the null cannot be rejected.

\footnotetext{
${ }^{8}$ Available upon request.
} 


\section{Conclusions}

The central objective of this paper is to estimate the effect of external finance dependence and financial development under relatively weak functional form assumptions. Formal testing rejects the parametric function in favor of its semiparametric counterpart. The results indicate that the interaction between external finance dependence and financial development has a non-linear effect on growth rates, and exhibits diminishing returns to improvement in financial development.

Apart from using the new semiparametric methodology, the findings in this paper suggest a fresh explanation for the pattern of industry specialization and growth across countries. For an improvement in financial development, financially underdeveloped countries experience greater increase in growth rates than financially developed countries in the industries that are more dependent on finance.

\section{References}

Blundell, R. and A. Duncan. 1998. "Kernel Regression in Empirical Microeconomics." Journal of Human Resources 33:62-87.

Ciccone, Antonio and Elias Papaioannou. 2006. "Adjustment to Target Capital, Finance and Growth." CEPR.

- 2007. "Red Tape and Delayed Entry." Journal of the European Economic Association $5(2-3): 444-58$.

—. 2010. "Estimating Cross-Industry Cross Country Models Using Benchmark Industry Characteristics." CEPR.

Fisman, Raymond and Inessa Love. 2007. "Financial Dependence and Growth Revisited." Journal of the European Economic Association 5 (2-3):470-79.

Fisman, Raymond and Virginia Sarria-Allende. 2010. "Regulation of Entry and the Distortion of Industrial Organization." NBER.

Hausman, J. 1978. "Specification Tests in Econometrics." Econometrica 46:1251-1271. 
Ju, Jiandong and Shang-Jin Wei. 2011. "When is Quanlity of Financial System a Source of Comparative Advantage." Journal of International Economics 84:178-87.

Melitz, Marc and Alejandro Cunat. 2012. "Volatility, Labor Market Flexibility, and the Pattern of Comparative Advantage." Journal of the European Economic Association 10 (2):225-54.

Newey, W., J. Powell, and F. Vella. 1999. "Nonparametric Estimation of Triangular Simultaneous Equations Models." Econometrica 67:565-603.

Nunn, Nathan. 2007. "Relationship-Specificity, Incomplete Contracts, and the Pattern of Trade." Quarterly Journal of Economics 122 (2):569-600.

Porta, Rafael La, Florencio Lopez de Silanes, Andrei Shleifer, and Robert W. Vishny. 1998. "Law and Finance." Journal of Political Economy 106 (6):1113-1155.

Rajan, Raghuram and Luigi Zingales. 1998. "Financial Dependence and Growth." American Economic Review 88 (3):559-586.

Romalis, John. 2004. "Factor Proportions and the Structure of Commodity Trade." American Economic Review 94 (1):67-97.

Schumpeter, J. A. 1911. A Theory of Economic Development. Cambridge, MA: Harvard University Press.

Yatchew, Adonis. 1997. "An Elementary Estimator of the Partial Linear Model." Economics Letters 57:1135-1143.

—. 1998. "Nonparametric Regression Techniques in Economics." Journal of Economic Literature 36:669-721.

—. 1999. "Differencing Methods in Nonparametric Regression: Simple Techniques for the Applied Econometrician." Manuscript, University of Toronto.

—. 2000. "Scale Economies in Electricity Distribution: A Semiparametric Analysis." Journal of Applied Econometrics 15:187-210. 


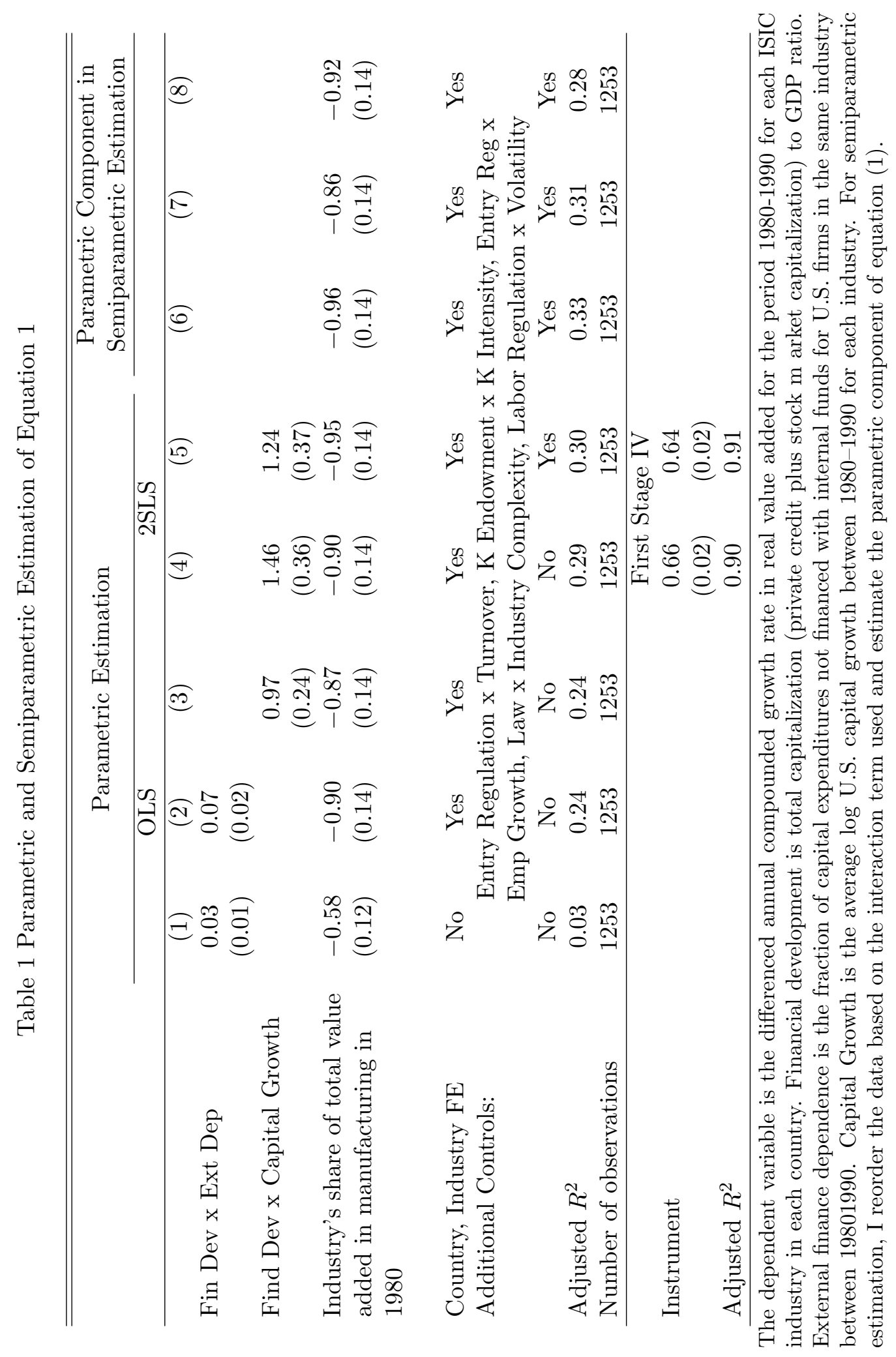



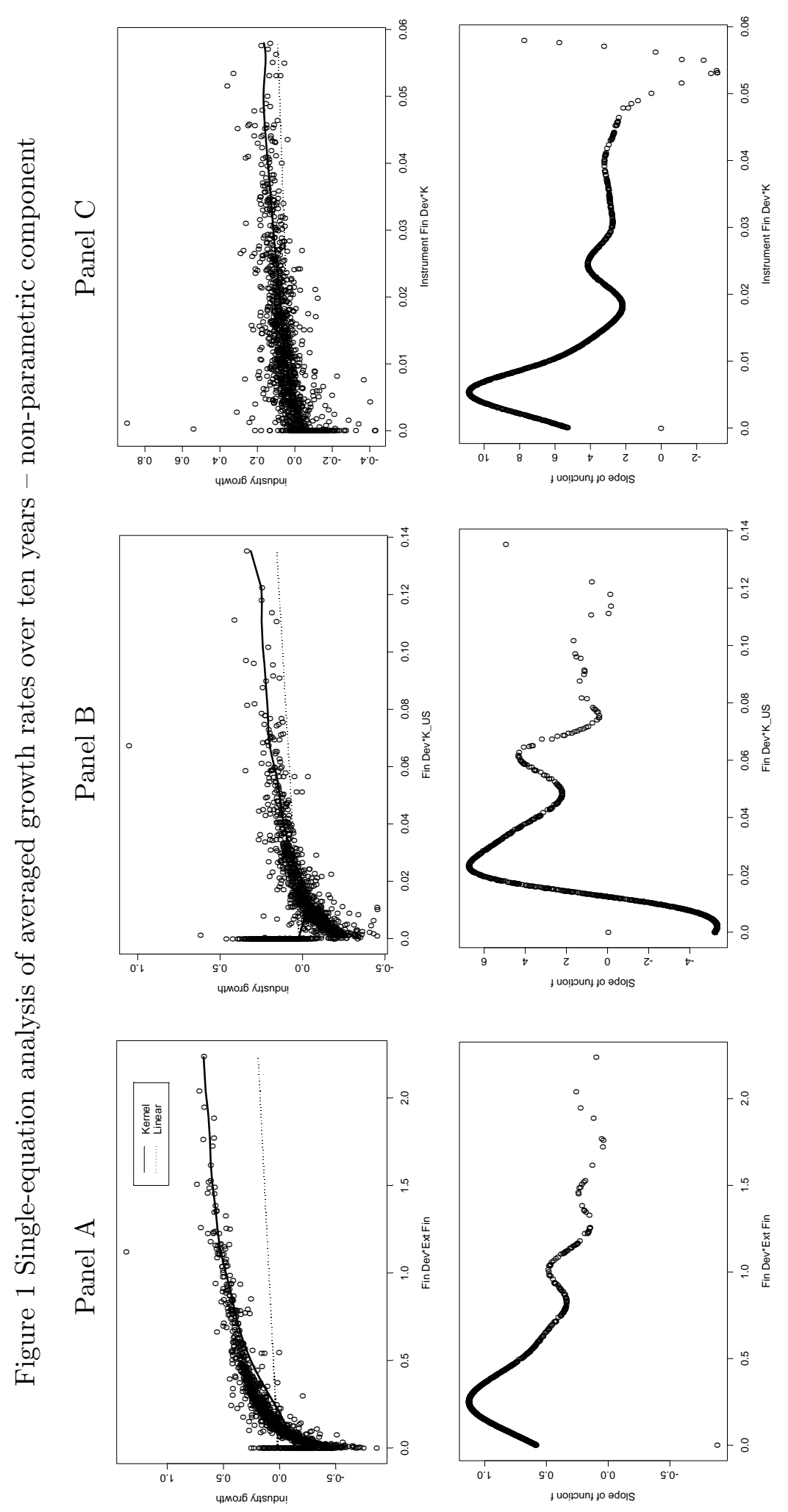